\title{
AC 2008-914: TEACHING SYSTEMS ENGINEERING PRINCIPLES USING A DESIGN PROJECT TARGETING AN INTERNATIONAL ROBOTIC COMPETITION
}

Scott Tippens, SPSU 


\title{
Teaching System Engineering Principles Using a Design Project Targeting an International Robotics Competition
}

\begin{abstract}
As systems grow more complex, it is critical that we impart basic systems engineering principles to our students so that they will become better prepared for future challenges in their professional careers. While these principles can be taught in a conventional classroom environment, the impact is far more engaging and dramatic if the students are required to apply these concepts to an actual system as they learn.

For the past several years, I have taught just such a course. Introduction to System Engineering and Robotics teaches students the principles of systems engineering as they design, model, build, and test an underwater autonomous vehicle designed to compete in the annual AUVSI Autonomous Underwater Vehicle Competition. With each iteration of the course, I have learned a great deal from the many successes and failures that are part of any such endeavor.

Some of the more challenging problems discussed in this paper are how to fairly evaluate student performance when each member of the class is performing significantly different tasks, how to obtain resources that often cost significantly more than most departmental budgets allow, and how to effectively integrate classroom topics into laboratory assignments.
\end{abstract}

An unexpected side benefit of the course has been the ability to discuss and have the students experience issues of leadership, teamwork, and ethics. To better promote this goal in later iterations of the course, each student was given a leadership roll in the class and numerous students absolutely blossomed in this environment.

Classwork culminated in a research presentation where the students were required to pick a significant engineering event and analyze it from a systems engineering perspective. Later classroom discussions were used to tie these concepts into their design experience with the Autonomous Underwater Vehicle.

By utilizing the design of an Autonomous Underwater Vehicle as a real-world laboratory for systems engineering, the students finished with a greater understanding of the complex concepts and concrete examples of their application. A course organized this way is definitely more difficult to teach but the rewards make the effort very worthwhile.

\section{Introduction}

Systems Engineering encompasses a broad area of study and involves a wide range of principles and practices that are important for any successful professional in all engineering disciplines. Because of this, it is important to instill in each engineering or engineering technology graduate some of the more fundamental principles so that they can carry these principles with them throughout their careers. 
To address these issues for our undergraduate students, an elective course was created to teach basic Systems Engineering principles. The goal of the course was certainly not to teach everything in the field, which would be impossible in one course, but to provide a well rounded overview of the fundamentals. I wanted the students to not just read about physical modeling but to experience it first hand. I did not want to just talk about the implication of poor interface design, I wanted the students to experience the problems themselves when they failed to completely define their subsystem interfaces. Nothing leaves an impression quite like personal experience and I want the students to experience Systems Engineering principles in action.

\section{Course Creation}

Since I have had great experience with active learning in the past and I really wanted to drive these principles home for the students, I decided to approach the teaching of this course differently. I wanted the students to not only learn the basic principles but to experience their application first hand. Competitions have always been a valuable activity for engaging students in their disciplines and, since competitions generally represent the creation of moderately complex systems, tying the course materials to a national competition seemed a natural fit.

I wanted the students to be challenged and I also wanted them to feel the work would be seen by a larger audience. After researching numerous possibilities, I chose the Association for Unmanned Vehicular Systems International's (AUVSI's) Autonomous Underwater Vehicle competition. ${ }^{1}$ The basic task for this competition involves the creation of an autonomous submarine robot that will navigate a specific underwater course utilizing a variety of sensing technologies such as sonar and vision. This competition provided numerous advantages including an international audience and a complex design challenge. It was also feasible to get started with a relatively small budget.

The course is called "Introduction to Systems Engineering and Robotics" and is considered a capstone elective for three of our degree programs. The course was initially offered as a special topic course but, due to its initial success, has been added to our regular undergraduate catalog. The course tends to be offered in the Spring of each year with the AUVSI competition occurring at the end of the Summer term. This gives the more dedicated students the opportunity to tweak the subsystems during the Summer term prior to the competition. The competition has been held in San Diego, California since we have been participating and does not show any signs of changing locations. This actually helps budgetary planning.

\section{Course History}

Introduction to Systems Engineering and Robotics was actually created and delivered for the first time in the Fall of 2000. The original target competition was an IEEE Southeast Regional student hardware competition. $^{2}$ The IEEE competition was again the target for Fall 2001, Fall 2004, and Fall 2005. Each time the IEEE competition was selected, we had a timing dilemma the rules were rarely finalized until more than half way through the class making the design requirements a moving target. This frustrated all involved in the project. 
The use of the AUVSI Autonomous Underwater Vehicle competition actually began in Fall 2002. We did not travel to competition during this term or during the Spring 2003 offering because we were just figuring out funding difficulties and, frankly, the vehicle just was not ready. During Summer 2004 we were finally ready and attended the competition for the first time. During the Spring 2005, Spring 2006 and Spring 2007 terms we also completed a design that went to competition and we continue to make the AUVSI competition our target design today.

One of the advantages of choosing and settling on an international competition is greater exposure for the students and our program. The students work is seen by other students from all over the country and the world and those that are selected to attend the actual competition get to interact with these same people. The 2007 competition not only featured prominent Universities from the United States but also included teams from Canada, India, and Japan. Such an international competition also improves how the students see themselves and their relationship to their chosen profession.

All total, this course has been offered in our program ten times. Each time I learned lessons for how to better organize, evaluate, and guide the students. And each time the course gets better at conveying Systems Engineering concepts.

\section{Course Organization}

The course structure is organized around fundamental Systems Engineering design steps. These steps were developed as a way to dovetail Systems Engineering concepts with classroom exercises and discussions. The fundamental steps addressed in this course are:

- Requirements Analysis

- Concept Exploration

- Functional Decomposition

- Subsystem Decomposition

- System Modeling and Risk Analysis

- Interface Development

- Subsystem Development

- System Integration/Validation

The class first discusses each topic in detail and explores them through various reading assignments. After each topic is discussed, the students then apply what they have learned to the current submarine design.

During requirements analysis, for example, the class thoroughly reviews the rules and regulations associated with the current competition and creates a list of system requirements. This list is also influenced by a thorough analysis of potential external environmental influences as well. Each element of the list is then placed into one of two categories: mandatory and optional. These results will then be used in the next phase of Systems Engineering we call concept exploration. 
After our theoretical discussions, concept exploration is conducted by dividing the class into groups of approximately four students each. These groups debate possible solutions for the previously derived system requirements and present their results to the class. The final phase of concept exploration consists of picking the best ideas from each groups presentations as a starting point for the submarine design.

Functional and Subsystem decomposition follows again with each first receiving theoretical consideration followed by the creation of appropriate materials relevant to the current design. During functional decomposition, the students will create a list of required system functions based upon the previously derived requirements. A sequence analysis is then performed to verify that the functional list is indeed complete. During sequence analysis, the class simulates a mock competition run using only the functions derived during functional decomposition. This is one of the more revealing sections of the course since students inevitably arrive at an incomplete initial list of system functions.

In subsystem decomposition, the final list of functions will be assigned to specific subsystems. Each subsystem will then be solely responsible for the functions they are assigned. Even in the case where functions seem to cross subsystem boundaries, it is important for the students to understand that only one subsystem ultimately 'owns' that function.

The next phase is system modeling and includes both physical and logical modeling. During the physical modeling phase, students utilize a variety of inexpensive materials such as foam board, wood, metal, wire, etc. to construct scale models of each component to be utilized in the final system design. This is without a doubt the most revealing exercise in the class. Issues such as component placement and cable routing become obvious and this inevitably results in a lengthy discussion among the students as to how these issues should be addressed. Logical modeling refers to the transfer of information from one subsystem/component to another subsystem/component. By exploring how information is passed, many issues related to system function can be avoided.

Risk analysis follows and the students are encouraged to explore what will happen when one or more components fail in the overall design. Each failure is tabulated and the impact to the overall system along with the probability of occurrence are estimated. Failures are then ranked based upon severity and likelihood and the class develops a contingency plan for the most severe and most probable of these failures. This is the phase that inevitably forces the class to revisit some of the previous steps and emphasizes the importance of feedback in the overall Systems Engineering process.

Interface Development is the next phase of the course where students completely define their physical, logical, and software interfaces (where appropriate). A good deal of time is spent in this phase since interface failures tend to set back development a great deal. In a one semester course, it is critical to avoid as many of these pitfalls as possible.

The next phase is subsystem development where each subsystem team works independently to develop their own subsystems. Prior to beginning this phase, the student subsystem teams use 
Pert and Gantt charts to plan out the development, integration, and validation tasks for their subsystems. The subsystem teams then integrate their tasks with the other subsystem's tasks resulting in a Pert and Gantt chart for the whole system. This process helps each student see the complexities and interdependencies of large scale system designs.

\section{Obtaining Resources and Budget}

Developing an autonomous underwater vehicle can be an expensive proposition and components are just one aspect of that cost. Other potential costs involve the registration fee, lab equipment, underwater test facility, and travel. The initial submarine from 2004 cost approximately $\$ 3000$ with travel expenses almost doubling that figure. The 2007 submarine by contrast cost in excess of $\$ 10,000$ dollars to build and that did not include travel expenses. To compound this budgetary dilemma, the top teams in the competition easily spend much more than this amount.

Thankfully, there are many ways to offset these costs. The most critical element of our teams ability to compete on the other side of the country is the support of our Alumni Association. Each year we have gone to competition, the University Alumni Association has paid the travel expenses for those students selected to attend the competition.

Funding for much of the construction has been secured through the University Student Government Association (SGA). The SGA provides funds for student competition teams throughout the University and they have been very good about supporting the component and equipment needs of the AUVSI submarine team. The team also engages in a few outside fund raising activities to help supplement the budget. Another source of equipment comes from industry itself with the team receiving numerous donations and reduced price items for use in the submarine.

So how does this all integrate with the Introduction to Systems Engineering and Robotics course? Basically the AUV team is recognized as a student organization and as such has a financial account with both the SGA and the Alumni Association. The team has a captain and budget officer whose responsibility is to order all components when necessary. When students need components for their subsystems they contact the team captain or designated budget officer who then places the order and handles the money issues. These officers do not necessarily need to be part of the class but my experience is that things run much smoother when they are.

\section{Assessing Student Performance}

The most difficult aspect of this method for teaching Systems Engineering principles is, without a doubt, student assessment. In a standard laboratory, the instructor assigns the same or very similar project to all of the students in the course. Since each student is performing more or less the same tasks, evaluating their work is relatively straightforward.

In this course, however, each student is engaging in often times significantly different tasks when compared with his/her classmates. One student, for instance, may be working on designing the active filters for a sonar system while another student is writing system level code for component-to-component communication - completely different tasks with completely different 
design issues. Teaching such a course is difficult but fairly assessing student performance is a real challenge - at least it was at first.

Having taught this course so many times, I have finally found an assessment strategy they works both for me and for the students as well. What do I mean by 'for the students as well'? Basically, when two people are being evaluated in the same class for two different tasks, the other students tasks naturally look much simpler than your own. This can led to resentment and feelings of inequity. Thankfully I never experienced any real strong feelings of this nature but they were definitely there to a small degree in the early years.

The solution turns out to be very easy - let the students partially determine their own grading rubric. Once students have been divided into their respective subsystem teams, they will be making a list of milestones for their particular subsystem as part of the normal design process. For assessment purposes, each student should then take full responsibility for a fair division of the milestone goals. (It should be noted that sometimes it is necessary to divide a number of the goals into subgoals to make this process work). I then review the agreed upon division and - this is important - I assign the relative point values for each goal.

When I allowed student to assign their own point values in the past, the results were mixed. Some students (though not many) would try to assign higher weights to easier tasks and lower weights to the more difficult ones. The majority, however, would simply divide the points evenly without regard to difficulty level. Either way, the results did not represent a fair weighting for assessment. When I determined the weight assignments, however, it ensured a more equitable distribution since I could base the weights on my experience with past classes.

It is also important to note that for this to work, each and every milestone task must be measurable. In order to drive this point home, I require the students to describe in great detail how they plan to demonstrate completing a milestone task. This does require a little more work initially but it ensures a more pleasant experience as the semester comes to an end. When the milestones are difficult to measure or vague, it leaves lots of room for creative interpretation generally to the detriment of the overall system.

While milestones do not represent the only assessment vehicle for this course, they are the most diverse in nature and require special attention. The remainder of the students assessment comes from class quizzes, research papers, and research presentations.

\section{Student Trip Selection Process}

Selecting which students go to the competition has not been as difficult a task as I initially imagined. By the end of the term, the strongest students make themselves well known and by the time the plane tickets must to be purchased, a nice core of exceptional students forms on its own. 


\section{Research with Systems Engineering Focus}

The concepts of the course are further augmented utilizing a term research project. Each student is asked to pick a system failure in an area that interests them. Examples of topics in the past include structural failures in buildings, high-speed train accidents, interplanetary probe mission failures, and electronic device failures.

Once each student has determined a topic, they are required to write a research paper on the topic and present their findings to the class in a formal presentation. The students are told that the focus is not the failure in question but what caused the failure and how it relates to the Systems Engineering concepts we have discussed in class. The addition of this research project further solidifies the basic concepts they have been experiencing throughout the course.

\section{General Student Feedback}

Numerous students from past classes have contacted me while working in industry to share their experiences. One student sent me an email explaining how impressed his employer was with the fact that he understood and applied the principles of physical modeling to his designs. Specifically the employer commented on how wonderful it was to see schools focusing on these fundamental design principles.

Another student commented on how he used the principles he learned in class to successfully make it through one of our departments most difficult design courses. It was particularly enlightening to hear how he described talking with the other groups about their process and how they could do it much better. You know you have reached someone when they not only use what they have learned but pass that information on to others.

I even have past students sending me materials for class from industry. I recently had a student send me a physical model for a subsystem used in his company. I plan on using this model as part of this terms course.

\section{Survey Results}

In an attempt to get broader and more representative feedback for the success of the course, I decided to implement a web based survey. The staff in the ECET office helped setup and create a survey using the SurveyMonkey.com survey tool for the Spring 2005, Spring 2006, and Spring 2007 courses. These were the terms where we felt confident we could still contact a majority of the students.

There were a total of 19 respondents to the survey. As it turns out, the survey population was a mix of recent graduates working in industry and current students nearing graduation. This mixture actually provided a diversity of helpful and often surprising responses. The results are summarized in the following charts: 


\section{Responses for Question 1:}

To what degree do you feel you've been able to apply the systems engineering concepts you learned in class to later industry or course work?

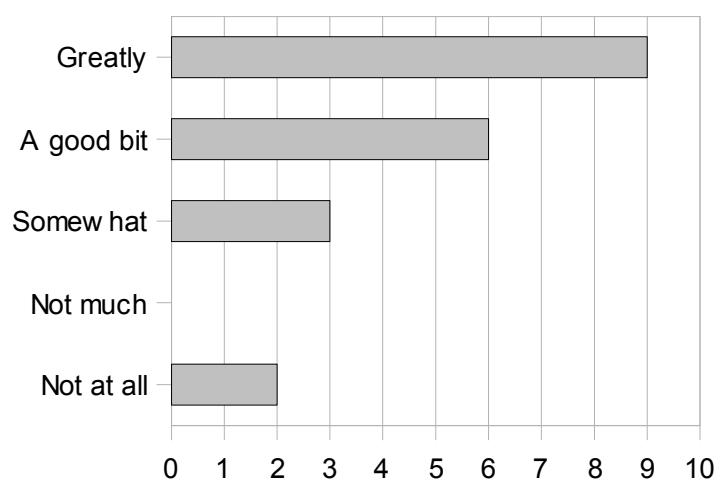

Responses for Question 2:

The course was structured so that as we learned new concepts in systems engineering we immediately applied them to our submarine design. How successful do you feel the course structure was compared to a conventional lecture/test course?

\section{Responses for Question 3:}

What concept was the most valuable?

Responses for Question 4:

What concept was the least valuable?

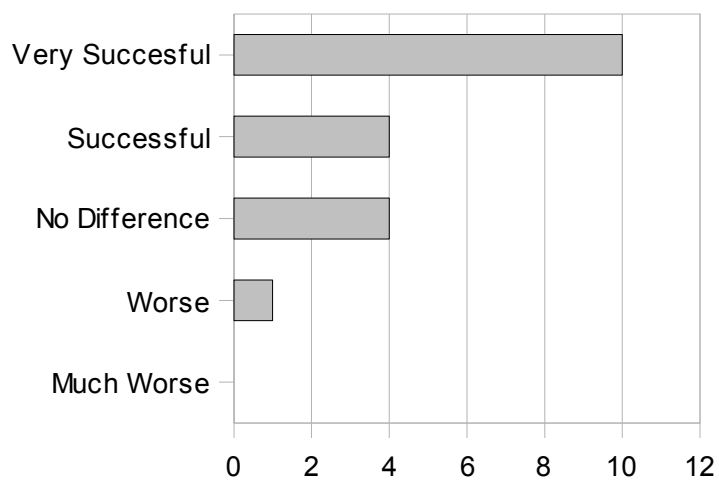

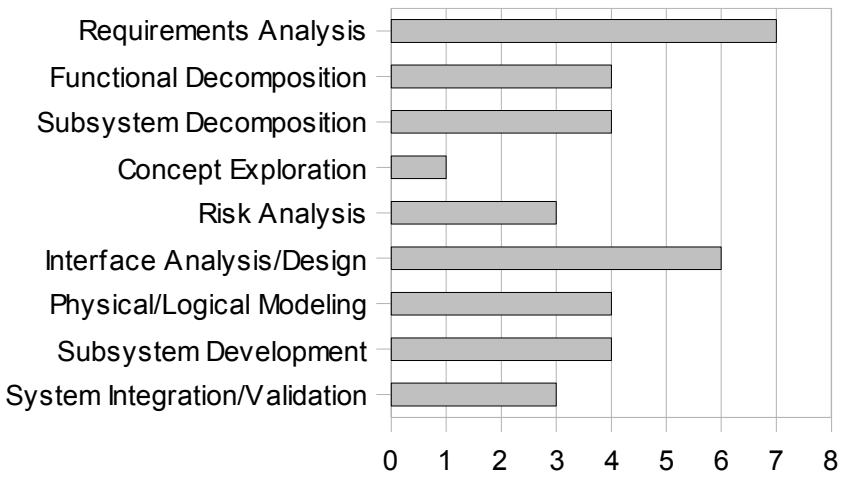

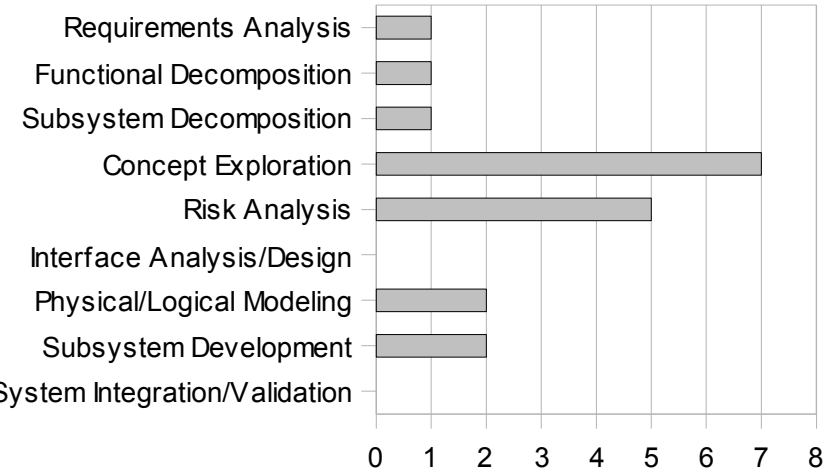


In general, it appears the students felt the course was valuable and the structure of the course was beneficial. I was most surprised by the spread for questions 3 and 4, however. It was always my intent to emphasize each aspect of systems engineering equally but it appears risk analysis and especially concept exploration did not fair well. The results may not indicate that these areas are viewed as unimportant but that the general consensus was they were the least important as a whole. Since I consider risk analysis to be extremely important when compared to the other areas, I need to make some adjustments in future classes.

The survey also included numerous opportunities for students to provide written feedback and the number and volume of responses I received was surprisingly high. All total, the student responses filled 8 printed pages. I've quoted a few representative passages below.

"During the class, long before we started building and ordering parts, Professor Tippens made us hammer out a plan. A plan for our subsystem and then coordinate our plan with other subsystems. The longer I work in industry I observe that this is the same game plan that companies use to work on larger projects that require more than a couple of people. Although I found this process annoying at first because I was ready to build, I see the benefit in large project planning now instead of rushing in."

"Much of my time in industry has been spent in obsolescence mitigation and hardware redesign. ... The systems engineering approach not only increased the maintainability of the systems but reduced the build costs while increasing the reliability of the end product."

"The SE course structure more closely resembles the "real world" environment that I work in and was a better gauge of my performance in industry."

"Employers really liked hearing about the AUV team during interviews"

\section{Conclusions}

After teaching this course for 7 years (10 times total), it has become clear that the most effective way to convey basic Systems Engineering principles is through the use of a design project. The design project gives the students something concrete to associate with the abstract theoretical concepts. Basically they learn what functional decomposition is then perform a functional decomposition on the class design project. They learn what physical modeling is then construct your own physical model. Active learning of this nature engages all of the senses and leads to longer retention of the concepts. It takes a little more effort to teach a course like this but, in my experience, the results are more than worthwhile. 


\section{Bibliography}

1. Association for Unmanned Vehicular Systems International, Unmanned Systems Online, International Autonomous Underwater Vehicle Competition, http://www.auvsi.org/competitions/water.cfm

2. IEEE Southeast Con, http://www.southeastcon.org/

3. Systems Engineering and Analysis, Fourth Edition, Blanchard \& Fabrycky, Prentice Hall, 2006

4. What is Systems Engineering? A Consensus of Senior Systems Engineers, Terry Bahill \& Frank F. Dean, 2007, http://www.sie.arizona.edu/sysengr/whatis/whatis.html (a great resource for students beginning their studies in Systems Engineering).

5. SPSU AUV Team Website

http://www.spsuauv.org 